\title{
The Financial Evaluation Research of Real Estate Enterprise based on the Fuzzy Comprehensive Evaluation Method
}

\author{
Zhongfu QIN, Xianrong WEI, Liqing MENG \\ Construction engineering college, ZhejiangUniversity, Hangzhou, 310058, China
}

\begin{abstract}
To change the status quo of China's real estate enterprises, and improve enterprise survival capacity, profitability, development capacity, etc., it's necessary to carry out real estate enterprise financial performance evaluation. First, design a set of more scientific and reasonable system of real estate enterprise financial performance indicators on the basis of the evaluation index selection principle; Then use analytic hierarchy process (AHP) to determine the relative importance of each index, and use fuzzy comprehensive evaluation method to construct a real estate enterprise financial performance evaluation model; At last, prove the practicability and rationality of this research. Fuzzy comprehensive evaluation method.

KEYWORD: real estate company; financial evaluation; fuzzy comprehensive evaluation method
\end{abstract}

\section{INTRODUCTION}

Harry (1911) designed the world's first standard cost system, which had become the prototype of the enterprise performance evaluation [1]. Until the 1980s, Brigham E mainly use financial management indicators to study the analysis of enterprise performance evaluation [2]. From the 1980s to the 1990s, the research direction initially formed, it was mainly financial index, and properly considering the effects of non-financial [3]. Since the 1990s, scholars such as STEM. J.M are mainly to build the corporate performance evaluation index system [4-6]. And the research mainly involves the following two aspects: one is about the construction and evaluation research of the corporate performance evaluation index system; the second is about empirical research and application of the corporate financial performance evaluation.

In Chinese academic circles, the research of the company's financial performance evaluation started relatively late. Ming-hua Shi[7] (2002) through the comprehensive analysis of the relevant company performance evaluation rules and operating rules, and analysis the applicability of the evaluation rules and operating rules of foreign companies, he put forward that evaluating of the real estate company's enterprise performance are from four aspects, the enterprise's financial indexes, growth potential, management, and customer satisfaction. Tiezhu Shao[8] (2013) listed 25 real estate companies and selected 12 financial index to do factor analysis. He studyed the real estate listed company financial performance from the profit ability, debt paying ability, operating ability and development ability. Ming-hua shi and Tiezhu Shao's analysis respectively have his focus.

In this paper, on the basis of previous scholars research, the authors try to build a more perfect financial performance evaluation index system, and evaluate of enterprise financial situation through the perspective of qualitative and quantitative.

\section{EVALUATION INDEX SYSTEM OF FINANCIAL PERFORMANCE}

\subsection{The index system principles}

Financial indicators must can reflect the financial position of real estate enterprise and must be scientific and reasonable. In addition, the realistic meaning and importance of financial indicators depend whether it was selected into the index system. Further more, index system should reflect systemic and gradation. Comprehensive above, in the process of index selection should follow the following principles: integrity, scientific, systematic, comprehensiveness, adaptability, practical and importance[9].

\subsection{The index system}

The traditional financial performance indicators system that evaluate the real estate listed company financial performance mainly are profit ability, operation ability, debt paying ability and development ability. But in practice, the four 
indicators can not comprehensive enough reflect the enterprise's financial situation.

At present, more and more real estate listed companies use earnings per share, net assets per share, price-to-book, price-to-sales ratio and so on to evaluate the profit ability, and these indicators reflect the profitability of shareholders in the listed company's ; Secondly, in the process of enterprise development today, the cash flow can reflect the essence of enterprise, and it is the authoritative evaluation in many value evaluation index, which decides the enterprise's thriving; Then, the financial risk can not be ignored in the process of financial operation and management. The owners and managers must make effective measures to prevent risks, such as establishing risk early warning system, etc.; Finally, the enterprise's solvency is necessary divided into short-term solvency and long-term solvency, because they can reflect the financial soundness of long-term and short-term respectively.

Based on the above analysis, this study will choose the profit ability, operation ability, short-term solvency, long-term solvency, development capacity, shareholder profitability, cash flow ability and level of risk to be the financial index, as shown in the first column, the third column, and the fifth column of table 3-2.

\section{FINANCIAL PERFORMANCE EVALUATION INDEX SYSTEM MODEL}

\subsection{AHP to determine the index weight}

According to the hierarchy of the connection and the parallel relationship between real estate company's financial performance evaluation indexes, the AHP method arrangesthem into several levels from high to low, and compare the importance of any two contrast factors in the same levels; then, construct comparative judgment matrix; And using mathematical method to calculate the characteristic root of the judgement matrix; last, various factors weights are calculated, and the consistency check is needed. For example, three factors weights of the short-term solvency $A_{3}$ is solved as following, table 3-1, and Table 3-2 is the financial evaluation index weight.

This study using 4 class rating, divided into excellent, good, medium and poor.

\subsection{Fuzzy comprehensive evaluation method evaluae index system}

(1) Factors layer

The establishment of the single factor $\mathrm{U}$ ( $A_{1}$, for example). Single factor collection

$U_{\text {factors }}=\left\{U_{A_{11}}, U_{A_{12}}, U_{A_{13}}\right\}$
(2) Establish the fuzzy comprehensive evaluation

Evaluation set $V=\left\{v_{1}, v_{2}, \ldots v_{n}\right\}$, which $v_{i}(i=1,2, \ldots n)$ represent different levels of the evaluation results.

(3) Establishing single factor fuzzy evaluation matrix $\mathrm{R}$

$\mathrm{R}$ represents a mapping from $\mathrm{U}$ to $\mathrm{V}$ of fuzzy evaluation matrix, $R=\left\{\mu_{i j} \mid i=1,2, \ldots, n, j=1,2, . ., m\right\}$

For example, evaluation matrix $R_{A_{1}}$ of $U_{A_{1}}$ is showed as follows:

$R_{A_{1}}=\left[\begin{array}{llll}\mu_{11} & \mu_{12} & \mu_{13} & \mu_{14} \\ \mu_{21} & \mu_{22} & \mu_{23} & \mu_{24} \\ \mu_{31} & \mu_{32} & \mu_{33} & \mu_{34}\end{array}\right]$

$\mu_{11}$ said the membership degree of factor $A_{11}$ (Operating margin) in the $U_{A_{1}}$ to evaluate $V_{1}$ (optimal), it represents the ratio that operating margin was rated as excellent.

Suppose that there are factors $A_{11}, 20 \%$ experts say it's excellent, $30 \%$ think it's good, $40 \%$ think medium, and $10 \%$ of the experts think the poor; $A_{12}$ is so, $10 \%, 20 \%, 50 \% ; A_{13}$ is just so, $10 \%, 40 \%$, $50 \%, 0 \%$. then

$$
R_{A_{1}}=\left[\begin{array}{cccc}
0.2 & 0.3 & 0.4 & 0.1 \\
0.1 & 0.2 & 0.5 & 0.2 \\
0.1 & 0.4 & 0.5 & 0
\end{array}\right] .
$$

(4) Calculation fuzzy comprehensive evaluation set $B$ of factors layer's

From $B_{A_{1}}=W_{A_{1}} \cdot R_{A_{1}}$, through calculating, getting the fuzzy comprehensive evaluation set $B_{A_{1}}$ of indicators set, at the same time to ask $B_{A_{2}}, B_{A_{3}}, B_{A_{4}}, B_{A_{5}}, B_{A_{6}}, B_{A_{7}}, B_{A_{8}}$, so $B_{\text {factors }}=\left\{B_{A_{1}}, B_{A_{2}}, B_{A_{3}}, B_{A_{4}}, B_{A_{5}}, B_{A_{6}}, B_{A_{7}}, B_{A_{8}}\right\}$

(5) To calculate the fuzzy comprehensive evaluation results

$$
R_{A}=B_{\text {factors }}, B_{\text {index }}=W_{A} \cdot R_{A}
$$

So after calculating the total index layer set, according the principle of maximum membership degree in fuzzy mathematics comprehensive evaluation method, the maximum $b_{k}\left(b_{k}=\max \left\{b_{j}\right\}\right)$ in fuzzy comprehensive evaluation set $B_{\text {index }}$, relative evaluation element $V_{k}$ is the level of financial performance.

\section{CASE ANALYSIS}

Take a listed real estate companies in zhejiang province for example, through the index practical value compared with the standard values and combining the expert scoring, gain the single factor fuzzy evaluation results, as shown in table 4-1. 
Table $3-1 A_{3}$ index weight

\begin{tabular}{|c|c|c|c|c|c|c|}
\hline \multicolumn{4}{|c|}{$A_{3}$ judgment matrix } & \multirow{2}{*}{ Continuous multiplication } & The NTH root of the product & The normalized processing W \\
\cline { 1 - 4 }$A_{3}$ & $A_{31}$ & $A_{32}$ & $A_{33}$ & & 2.080 & 0.600 \\
\hline$A_{31}$ & 1 & 3 & 3 & 9.000 & 0.693 & 0.200 \\
\hline$A_{32}$ & $1 / 3$ & 1 & 1 & 0.333 & 0.693 & 0.200 \\
\hline$A_{33}$ & $1 / 3$ & 1 & 1 & 0.333 & \\
\hline
\end{tabular}

Table 3-2 Financial evaluation index weight

\begin{tabular}{|c|c|c|c|c|}
\hline The total index & $\begin{array}{c}\text { Points index } \\
\text { weight }\end{array}$ & Points index & Factors & $\begin{array}{l}\text { Factors } \\
\text { weight }\end{array}$ \\
\hline \multirow{24}{*}{$\begin{array}{l}\text { the evaluation } \\
\text { indexe of } \\
\text { financial } \\
\text { performance }\end{array}$} & 0.395 & \multirow{3}{*}{$A_{1}$ profit ability } & $A_{11}$ Operating margin & 0.45 \\
\hline & & & $A_{12}$ Net interest rates of sales & 0.35 \\
\hline & & & $A_{13}$ Return on assets & 0.2 \\
\hline & 0.268 & \multirow{4}{*}{$A_{2}$ operation ability } & $A_{21}$ The velocity of accounts receivable & 0.19 \\
\hline & & & $A_{22}$ Inventory turnover & 0.06 \\
\hline & & & $A_{23}$ The velocity of accounts payable & 0.48 \\
\hline & & & $A_{24}$ The velocity of total assets & 0.27 \\
\hline & 0.169 & \multirow{3}{*}{$A_{3}$ short-term solvency } & $A_{31}$ Current ratio & 0.6 \\
\hline & & & $A_{32}$ Quick ratio & 0.2 \\
\hline & & & $A_{33}$ Cash ratio & 0.2 \\
\hline & 0.169 & \multirow{4}{*}{$A_{4}$ long-term solvency } & $A_{41}$ Asset-liability ratio & 0.375 \\
\hline & & & $A_{42}$ Current assets ratio & 0.125 \\
\hline & & & $A_{43}$ Fixed assets ratio & 0.375 \\
\hline & & & $A_{44}$ Long-term debt ratio & 0.125 \\
\hline & 0.104 & \multirow{2}{*}{$A_{5}$ development capacity } & $A_{51}$ Growth rate of total assets & 0.67 \\
\hline & & & $A_{52}$ Net profit growth rate & 0.33 \\
\hline & 0.068 & \multirow{3}{*}{$A_{6}$ shareholder profitability } & $A_{61}$ Earnings per share & 0.21 \\
\hline & & & $A_{62}$ P/e ratio & 0.24 \\
\hline & & & $A_{63}$ Net assets per share & 0.55 \\
\hline & 0.065 & \multirow{2}{*}{$A_{7}$ cash flow ability } & $A_{71}$ Cash flow ratio & 0.75 \\
\hline & & & $A_{72}$ Enterprise free cash flow & 0.25 \\
\hline & 0.042 & \multirow{3}{*}{$A_{8}$ risk ability } & $A_{81}$ Financial leverage coefficient & 0.49 \\
\hline & & & $A_{82}$ Operating leverage coefficient & 0.34 \\
\hline & & & $A_{83}$ Comprehensive lever & 0.16 \\
\hline
\end{tabular}

Take a listed real estate companies in zhejiang province for example, through the index practical value compared with the standard values and combining the expert scoring, gain the single factor fuzzy evaluation results, as shown in table 4-1.

Acording $\mathrm{B}=\mathrm{W} \cdot \mathrm{R}$, take $\mathrm{A}_{1}$ for example,

$$
B_{A_{1}}=\left[\begin{array}{lll}
0.45 & 0.35 & 0.2
\end{array}\right] \cdot\left[\begin{array}{cccc}
0.45 & 0.3 & 0.35 & 0 \\
0.1 & 0.55 & 0.35 & 0 \\
0.2 & 0.5 & 0.3 & 0
\end{array}\right]
$$

$=\left[\begin{array}{llll}0.278 & 0.428 & 0.340 & 0\end{array}\right]$
The calculateof remaining points index evaluation results is similar, as shown below

$B_{A_{2}}=\left[\begin{array}{llll}0.284 & 0.415 & 0.202 & 0.099\end{array}\right], B_{A_{3}}=\left[\begin{array}{lllll}0.485 & 0.380 & 0.135 & 0\end{array}\right]$,

$B_{A_{4}}=\left[\begin{array}{llll}0.133 & 0.373 & 0.302 & 0.192\end{array}\right], \quad B_{A_{5}}=\left[\begin{array}{llllll}0.567 & 0.333 & 0.100 & 0\end{array}\right]$,

$B_{A_{6}}=\left[\begin{array}{llll}0.284 & 0.276 & 0.440 & 0\end{array}\right], B_{A_{7}}=\left[\begin{array}{lllll}0.503 & 0.382 & 0.116 & 0\end{array}\right]$,

$B_{A_{8}}=\left[\begin{array}{llll}0.338 & 0.455 & 0.208 & 0\end{array}\right]$

Total index of the evaluation results $B_{A}=\left[\begin{array}{llll}0.415 & 0.505 & 0.319 & 0.059\end{array}\right]$

According to the maximum membership degree principle, the company's financial performance evaluation result is good. 
Table 4-1 Single factor fuzzy evaluation results

\begin{tabular}{|c|c|c|c|c|}
\hline Factors layer & optimal & good & medium & poor \\
\hline $\begin{array}{ll}A_{11} & \text { Operating margin } \\
\end{array}$ & 0.45 & 0.3 & 0.35 & 0 \\
\hline$A_{12} \quad$ Net interest rates of sales & 0.1 & 0.55 & 0.35 & 0 \\
\hline$A_{13} \quad$ Return on assets & 0.2 & 0.5 & 0.3 & 0 \\
\hline$A_{21}$ The velocity of accounts receivable & 0 & 0.2 & 0.3 & 0.5 \\
\hline$A_{22}$ Inventory turnover & 0 & 0.44 & 0.5 & 0.06 \\
\hline$A_{23}$ The velocity of accounts payable & 0.48 & 0.28 & 0.24 & 0 \\
\hline$A_{24}$ The velocity of total assets & 0.2 & 0.8 & 0 & 0 \\
\hline$A_{31} \quad$ Current ratio & 0.6 & 0.3 & 0.1 & 0 \\
\hline$A_{32} \quad$ Quick ratio & 0.5 & 0.3 & 0.2 & 0 \\
\hline$A_{33} \quad$ Cash ratio & 0.2 & 0.7 & 0.1 & 0 \\
\hline$A_{41} \quad$ Asset-liability ratio & 0.1 & 0.4 & 0.5 & 0 \\
\hline$A_{42} \quad$ Current assets ratio & 0.1 & 0.3 & 0.6 & 0 \\
\hline $\begin{array}{ll}A_{43} & \text { Fixed assets ratio } \\
\end{array}$ & 0 & 0.3 & 0.3 & 0.4 \\
\hline$A_{44} \quad$ Long-term debt ratio & 0.4 & 0.5 & 0.1 & 0 \\
\hline$A_{51}$ Growth rate of total assets & 0.6 & 0.3 & 0.1 & 0 \\
\hline$A_{52}$ Net profit growth rate & 0.5 & 0.4 & 0.1 & 0 \\
\hline$A_{61}$ Earnings per share & 0.2 & 0.3 & 0.5 & 0 \\
\hline $\begin{array}{ll}A_{62} & \text { P/e ratio } \\
\end{array}$ & 0.24 & 0.26 & 0.5 & 0 \\
\hline $\begin{array}{ll}A_{63} & \text { Net assets per share }\end{array}$ & 0.55 & 0.25 & 0.2 & 0 \\
\hline$A_{71} \quad$ Cash flow ratio & 0.75 & 0.2 & 0.05 & 0 \\
\hline$A_{72}$ Enterprise free cash flow & 0 & 0.75 & 0.25 & 0 \\
\hline$A_{81}$ Financial leverage coefficient & 0 & 0.51 & 0.49 & 0 \\
\hline$A_{82} \quad$ Operating leverage coefficient & 0.34 & 0.66 & 0 & 0 \\
\hline$A_{83} \quad$ Comprehensive lever & 0.16 & 0.64 & 0.2 & 0 \\
\hline
\end{tabular}

\section{SUMMARY}

This paper uses the analytic hierarchy process and fuzzy comprehensive evaluation method to evaluate of the real estate enterprise financial performance. The result can provide direction and early warning information to the real estate company. But it can't deny defects of this method, both of analytic hierarchy process (AHP) and fuzzy comprehensive evaluation method need expert scoring. The subjectivity and inconsistencies of the experts can lead to the result not authority. So it needs more accurate quantitative method to evaluate of real estate company's financial performance in quantitative evaluation. Of course, quantitative evaluation is not necessarily accurate and applicable, but at least ruled out a great deal of subjectivity, which is also the next research direction of the authors.

\section{REFERENCES}

[1] EUGENE F BRIGHAM, JOEL F HOUSTON. Fundamental of financial management. 12th Edition. Ohio:
Cengage Learning, 2009: 145-148.

[2] Brigham E, Houston J. Fundamentals of financial management. Cengage Learning, 2011.

[3] Chagatai R., Demeanor F. Institutional ownership, capital structure and firm performance. Strategic management journal.1991.

[4] STEM.J.M, G.BENNETT STEWART, DONALD.H.C.J. The EVA financial management system. Bank of American Journal of Applied Corporate Finance, 1995, 6(12): 32-46.

[5] BACIDORE J M, BOQUIST J A. The search for the best financial performance measure. Financial Analysis Journal, 1997, 53(3): 10-11.

[6] DRUNKER P. Harvard business review on measuring corporate performance. Harvard business review, 1998, (2): 7-19.

[7] Ming-hua shi, Jing li "new economy" era in China's real estate listed companies performance evaluation index system frame of establishing. Journal of hunan university (social science edition), 2002, S1:58-61. [in Chinese]

[8] Shao Tiezhu.Sha Yu.The real estate listed company financial performance evaluation based on factor analysis. Science and technology and management, 2013, 01:90-93. [in Chinese]

[9] Xue Deng, Jiaming Li, Haojian Zeng, Junyang Chen, Junfeng Zhao. AHP weight calculation method for the analysis and application study. The practice and understanding of mathematics, 2012, cutflower production potentials: 93-100.[in Chinese] 